\title{
Numerical analysis of $\operatorname{In}_{2} \mathrm{~S}_{3}$ layer thickness, band gap and doping density for effective performance of a CIGS solar cell using SCAPS
}

\begin{abstract}
The effect of indium sulfide buffer layer's geometrical and electro-optical properties on the Copper-Indium-Gallium-diSelenide solar cell performance using numerical simulation is investigated. The numerical simulation software used is a solar cell capacitance simulator in (SCAPS). The innermost impacts of buffer layer thickness, band gap, and doping density on the cells output parameters such as open circuit voltage, short circuit current density, fill factor, and the efficiency were extensively simulated. The results show that the cell efficiency, which was innovatively illustrated as a two-dimensional contour plot function, depends on the buffer layer electron affinity and doping density by keeping all the other parameters at a steady state. The analysis, which was made from this numerical simulation, has revealed that the optimum electron affinity is to be $4.25 \pm 0.2 \mathrm{eV}$ and donor density of the buffer layer is over $1 \times 1017 \mathrm{~cm}-3$. It is also shown that the cell with an optimum thin buffer layer has higher performance and efficiency due to the lower optical absorption of the buffer layer.
\end{abstract}

Keyword: Buffer layer; CIGS; In2S3; SCAPS; Thin film 